\title{
The indoor climate and students' learning performance in schools
}

\author{
T.-A. Koiv, A. Mikola, A. Saar \& G. Silm \\ Department of Environmental Engineering, \\ Tallinn University of Technology, Estonia
}

\begin{abstract}
The paper gives an overview of indoor climate studies in various schools in Estonia. It is based on various measurements of indoor air temperature and $\mathrm{CO}_{2}$ concentration in six different schools and provides an overview of the principle of determining the $\mathrm{CO}_{2}$ level. The indoor climate in six school buildings was investigated and students' relative performance was determined.

The study showed that indoor air temperature in the classes of the studied schools is at a satisfactory level. At the same time even in renovated schools, there are problems with air quality (the $\mathrm{CO}_{2}$ level is usually very high and air change is modest). The outcome is low learning performance.

Because the ventilation in classrooms is modest, students' relative performance is not high. This study shows that well-organized ventilation in classrooms is important, not only from the aspect of indoor climate comfort, but also significantly affects students' performance.

To improve this situation it is necessary to raise the quality of renovation and the operational level of HVAC systems.

Keywords: indoor climate of classrooms, determination of the $\mathrm{CO}_{2}$ level, relative learning performance.
\end{abstract}

\section{Introduction}

Poor indoor air quality (IAQ) in indoor spaces, such as classrooms, can have adverse effects on the students' and teachers' comfort and pupils' learning performance.

Over short time scales (hours), poor IAQ causes discomfort, loss of attention and learning ability problems. On the other hand, sufficient ventilation rates in 
classrooms have been shown to improve students' performance, e.g. in mathematics and reading tests [1].

The air change rate (ACR) is not sufficient and generally much lower than the mandatory design requirements.

During classroom occupation, the indoor concentrations of carbon dioxide $\left(\mathrm{CO}_{2}\right)$ can rapidly reach the recommended limit values, and this is caused by an inadequate level of ventilation [2]. In the Netherlands several studies in primary schools showed that the $\mathrm{CO}_{2}$ concentration exceeded $1000 \mathrm{ppm}$ more than $80 \%$ of the time [3].

Indoor air pollutants might increase the chance of both long and short term health problems among pupils and staff, reduce teachers' productivity and degrade pupils' learning environment and comfort [4]. Studies done in the United States [5] indicated that good air quality in schools has enhanced attendance and reduced health problems among pupils. Research conducted on five classrooms in Hong Kong indicated that with inadequate ventilation the maximum $\mathrm{CO}_{2}$ level may reach $5900 \mu 1 / 1$ during a class [6].

Clements-Croome et al. [8] in their research of eight primary schools in increased by $7 \%$ due to the intervention of fresh air supply from $0.3-0.5$ to $16 \mathrm{l} / \mathrm{s}$ per person. This is supported by [8], in which small ventilation air flow rates will reduce not only comfort, but also schoolchildren's learning performance in classrooms. Improving classroom conditions can substantially improve the performance of school work by children [9].

Figure 1 shows very high $\mathrm{CO}_{2}$ concentration in classrooms with natural ventilation, which affects students' school performance. It can be seen that the increase in the $\mathrm{CO}_{2}$ level in a classroom with natural ventilation is about $1500 \mathrm{ppm}$ per school hour, which is higher than the maximum permitted level [10].

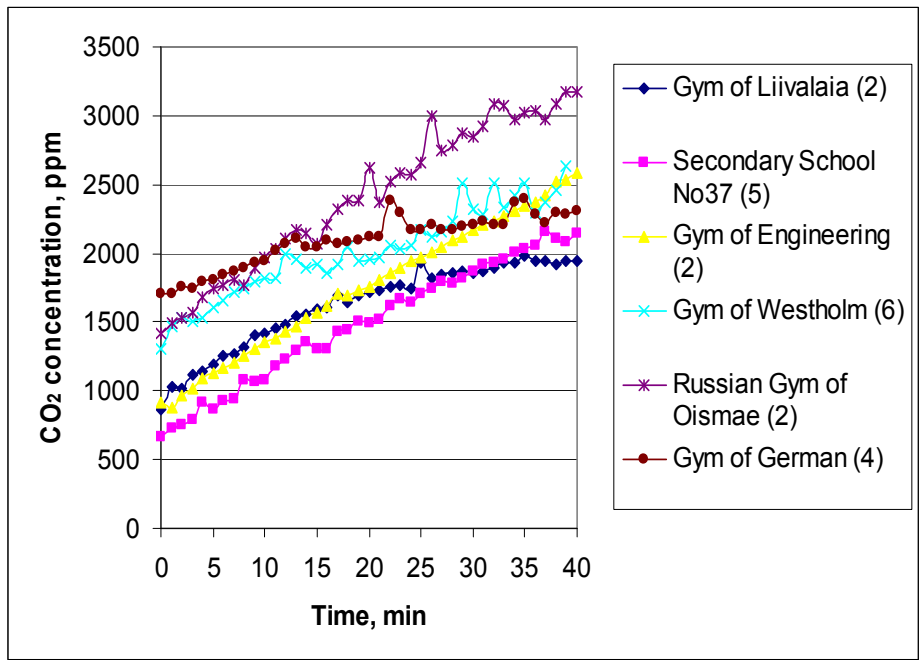

Figure 1: $\quad \mathrm{CO}_{2}$ concentration in the investigated classrooms during a class in different schools in Estonia [10]. 
The paper presents the results of the study into the dependence of learning performance on the indoor climate in four school buildings, which show significant shortcomings in the indoor air quality of the classrooms. All school buildings have mechanical supply-exhaust ventilation.

\section{Method}

This study is based on various measurements of indoor air temperature and $\mathrm{CO}_{2}$ concentration in six different schools in Estonia. The measurements were taken at the height of 1.2-2.5m from the floor level. HOBO data loggers (Onset Computer Corporation) and TelAire $7001 \mathrm{CO}_{2}$ sensors were used to measure the indoor air temperature and $\mathrm{CO}_{2}$ concentration. The values of the measured parameters were saved in every 1 minute. The air change in the classroom was calculated according to the change in $\mathrm{CO}_{2}$ concentration during the classes. The number of students in each class was also recorded.

Air change in a room can be determined by the $\mathrm{CO}_{2}$ concentration change using equation (1) [4].

$$
\frac{L}{V} \cdot \tau=-\ln \frac{\frac{m}{L}+C_{v}-C}{\frac{m}{L}+C_{v}-C_{o}}
$$

where:

$\mathrm{m}$ - carbon dioxide generation in the room,

$\mathrm{L}$ - air change in the room,

$\mathrm{V}$ - volume of the room or design volume,

$\mathrm{C}_{\mathrm{v}}$ - carbon dioxide concentration in external air (in supply air),

$\mathrm{C}$ - carbon dioxide concentration in room air (in exhaust air),

$\mathrm{C}_{\mathrm{o}}$ - carbon dioxide concentration in the air of the room at the beginning of human activity,

$\tau$ - time.

The air change results determined by formula (1) show good correlation with the measured values.

The dependence of relative performance on the air change in classrooms together with indicators by various researchers are shown in Figure 2 [15].

As indoor temperature deviations from the optimal values are small, the impact of this parameter on performance is small, up to $1 \%$. Therefore, only the influence of air change on the relative performance has been observed.

\section{Results}

The objects of investigation were six schools ( 5 secondary schools, one basic school) in Estonia, their general data are given in Table 1. These are mainly schoolhouses built in the1960s to 1980 s, which were renovated at the beginning of this century. 


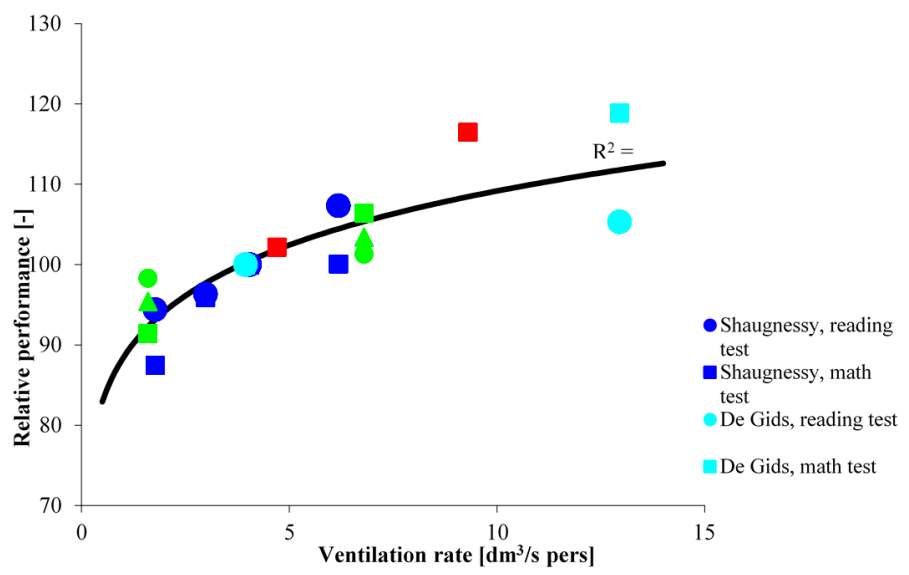

Figure 2: The dependence of relative performance on the air change in classrooms together with indicators by various researchers.

Table 1: General data of schools.

\begin{tabular}{|c|c|c|c|c|c|}
\hline School & $\begin{array}{c}\text { Number of } \\
\text { students }\end{array}$ & $\begin{array}{c}\text { Number of } \\
\text { classrooms }\end{array}$ & $\begin{array}{c}\text { Heated } \\
{\text { area } \mathrm{m}^{2}}^{2}\end{array}$ & $\begin{array}{c}\text { Year of } \\
\text { construction }\end{array}$ & $\begin{array}{c}\text { Year of } \\
\text { reconstruction }\end{array}$ \\
\hline A & 843 & 29 & 8174 & 1981 & 2007 \\
\hline B & 715 & 33 & 4662 & 1960 & 2003 \\
\hline C & 780 & 43 & 6628 & 1969 & 2007 \\
\hline D & 638 & 34 & 4586 & 1965 & 2005 \\
\hline E & 773 & 33 & 5466 & 1986 & 2006 \\
\hline F & 650 & 35 & 6589 & 1989 & $2007-2008$ \\
\hline
\end{tabular}

The indoor air temperature in the classrooms of the studied schools is shown in Figure 3. It can be seen from Figure 3 that the indoor air temperature is at a satisfactory level.

The comparison of schools by the $\mathrm{CO}_{2}$ level of the indoor air in the classrooms (cumulative graph) is given in Figure 4.

It can be seen from Figure 2 that the indoor air quality (on the basis of the $\mathrm{CO}_{2}$ level) is good in School A. However, in schools C, D and E, the situation is very serious. The air change levels in the classrooms determined by formula (1) are given in Table 2. The same table shows the learning performance by air quality which is determined by the Figure 2 .

Relative performance of students is determined on the basis of air change, the basic value is $61 / \mathrm{s}$ per student. The air flow rates in different schools by standard prEN 15521-II class, air change $1 /\left(\mathrm{s}\right.$ student) and $1 /\left(\mathrm{m}^{2} \mathrm{~s}\right)$ are presented in Figure 5.

The comparison of learning performance in the studied schools is given in Figure 6. The figure shows that in school $\mathrm{A}$ the air change and learning performance is good. However, in schools C, D and E the situation is very poor. 


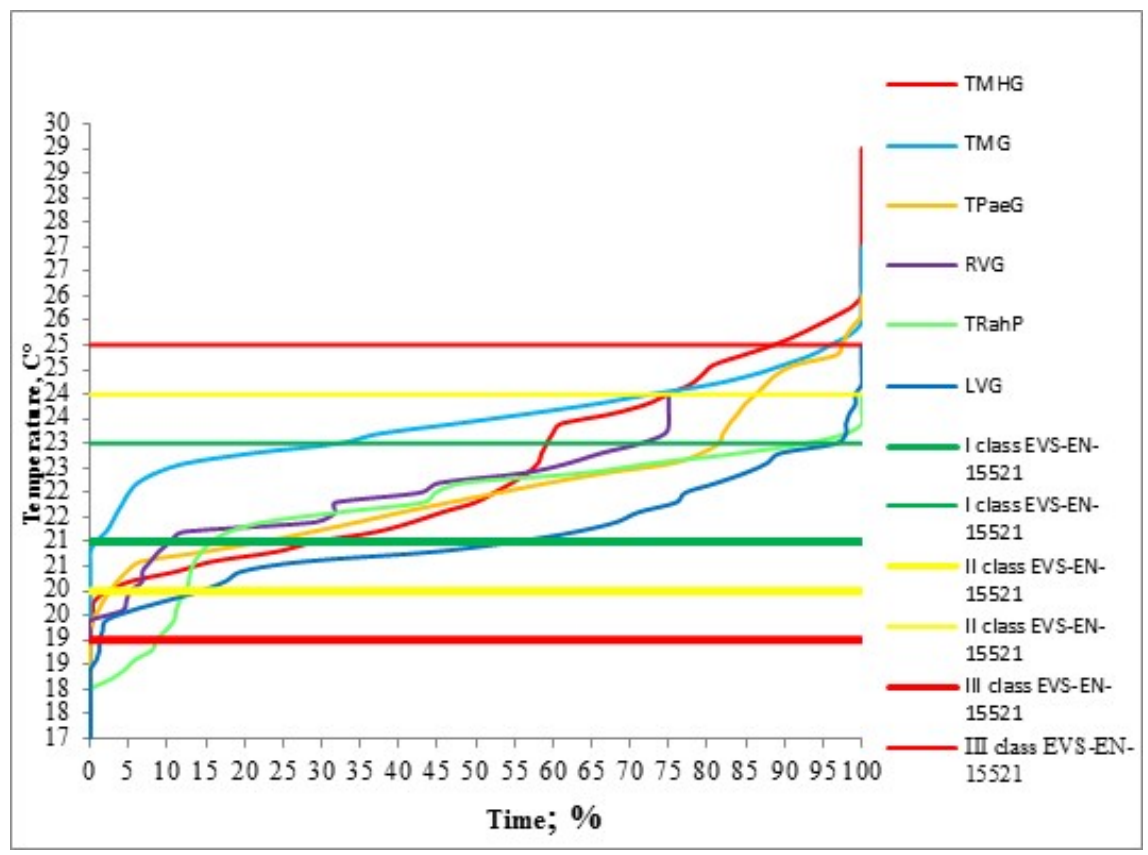

Figure 3: The indoor air temperature in representative classrooms of the six studied schools.

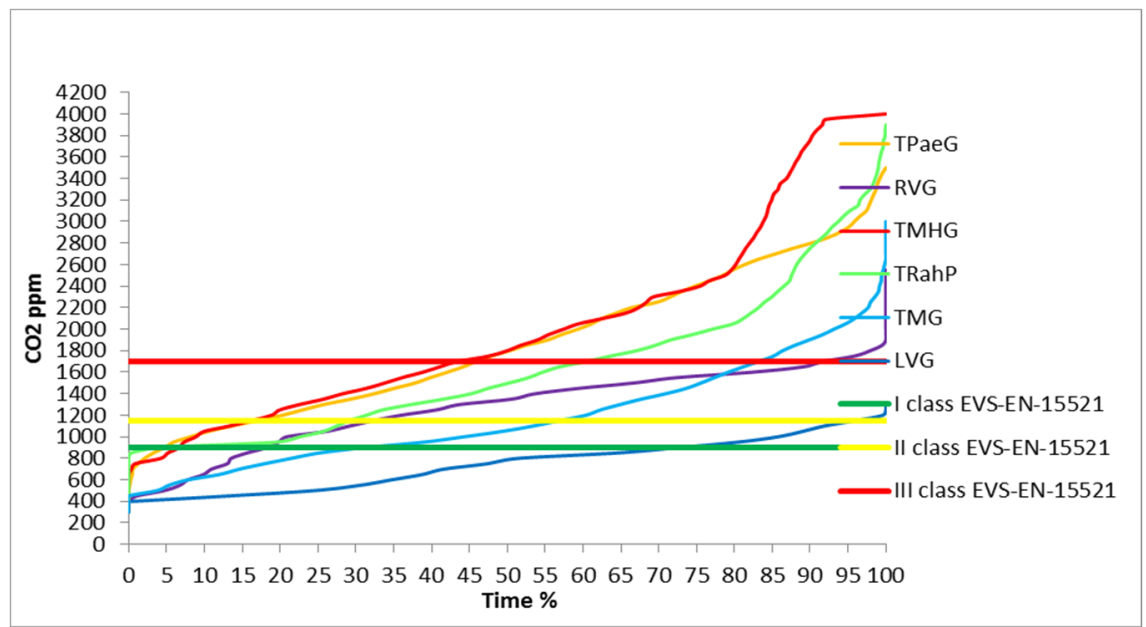

Figure 4: The comparison of schools by the $\mathrm{CO}_{2}$ level of the indoor air in the classrooms (cumulative graph). 
Table 2: Air change and learning performance in schools.

\begin{tabular}{|c|c|c|c|}
\hline School & \multicolumn{2}{|c|}{ Air change } & $\begin{array}{c}\text { Average performance } \\
\text { by air quality }\end{array}$ \\
\hline & $1 /(\mathrm{s} \cdot$ student $)$ & $1 /\left(\mathrm{s} \cdot \mathrm{m}^{2}\right)$ & $\%$ \\
\hline School A & 6.5 & 0.6 & 95.6 \\
\hline School B & 2.3 & 0.8 & 75.7 \\
\hline School C & 1.1 & 0.5 & 63.1 \\
\hline School D & 1.3 & 0.5 & 69.6 \\
\hline School E & 1.6 & 0.6 & 70.8 \\
\hline School F & 3.7 & 1.3 & 85.9 \\
\hline
\end{tabular}

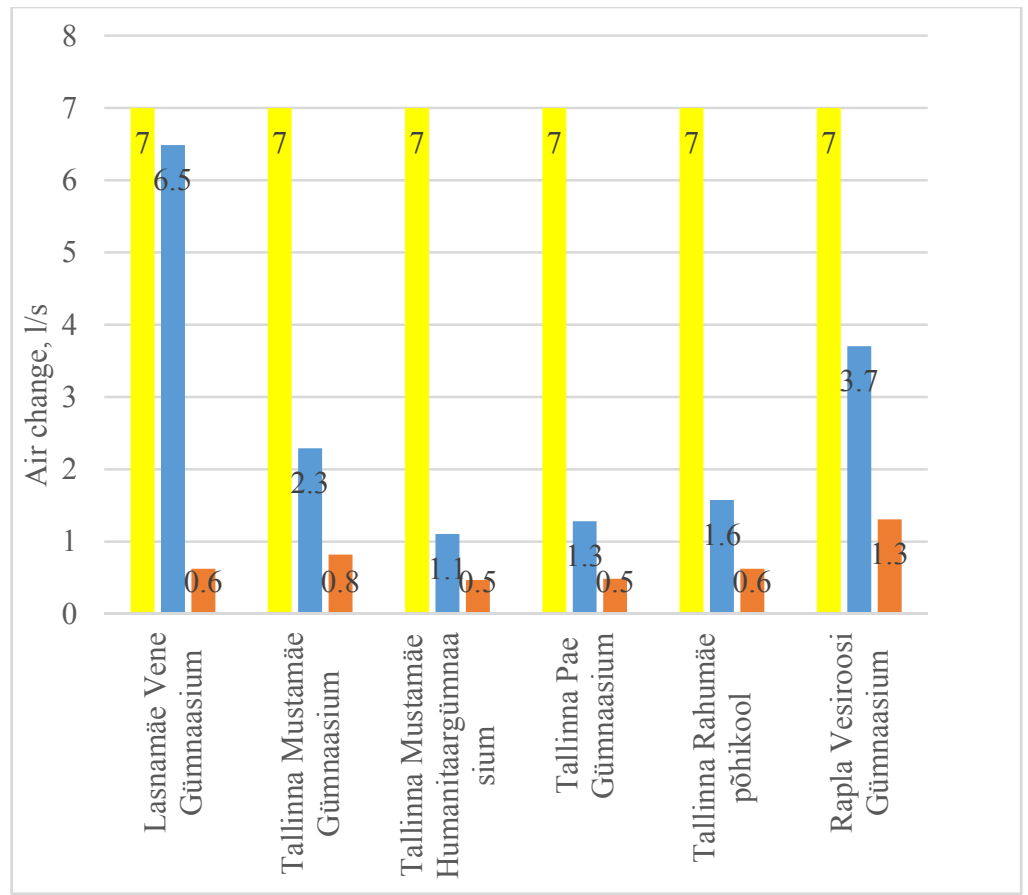

Figure 5: The air flow rates in different schools: by normative prEN 15521-II class (yellow), air change $1 / \mathrm{s}$ per student - blue; air change $1 /\left(\mathrm{m}^{2} \cdot \mathrm{s}\right)-$ brown. 


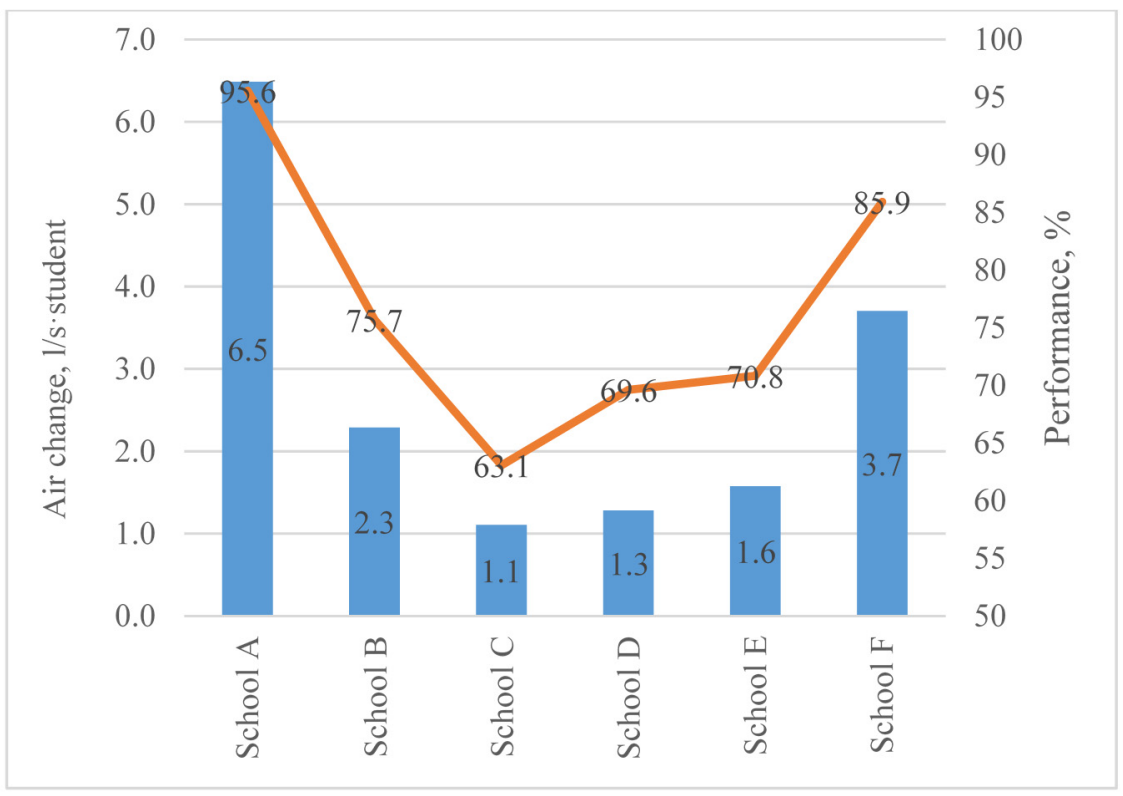

Figure 6: Learning performance by air quality: average air change/learning performance.

\section{Conclusion}

The article gives an overview of the indoor climate in six schools in Estonia.

The study showed that indoor air temperature in the classes of the studied schools is at a satisfactory level. At the same time even in renovated schools, there are problems with air quality (the $\mathrm{CO}_{2}$ level is usually very high and air change is modest). The outcome is low learning performance.

The reason for this is the poor performance of mechanical ventilation. On the one hand, this is due to the poor economic situation, schools will seek cost savings by reducing the air flow rates and the operating time of ventilation. On the other hand, the level of renovation is less than optimal. There are particular weaknesses in utility management.

To improve this situation it is necessary to raise the quality of renovation and the operational level of HVAC systems. The study clearly demonstrates that wellorganized ventilation in classrooms is important not only from the aspect of indoor climate comfort, but it also significantly affects students' learning performance.

\section{Acknowledgements}

The publication of this article was supported by the Estonian Research Council, with Institutional research funding grant IUT1-15 and by the project "Civil and Environmental Engineering PhD School, DAR9085”. 


\section{References}

[1] Indoor Air Quality in Schools - Improving Child Health and Learning Performance. https://www.google.com/search?q=google\&sourceid=ie7\& $\mathrm{rls}=$ com.microsoft:et:IE-Address\&ie $=\& o e=\# q=I n d o o r+A i r+$ Quality + in + Schools +-+ Improving + Child + Health + and + Learning + Performance $\&$ rls $=$ com.microsoft:et\%3AIE-Address 19.09.13

[2] Dijken, F., Bronswijk, J.E.M.H. van, Sundell, J., Indoor environment in Dutch primary schools and health of the pupils, Building Research and information, 34(5), pp. 437-446, 2006.

[3] Salleh, N. M., Kamaruzzaman, S. N., Sulaiman, R., Mahbob, N. S., Indoor Air Quality at School: Ventilation Rates and It Impacts Towards Children A review. 2nd International Conference on Environmental Science and Technology IPCBEE vol.6 (2011), IACSIT Press, Singapore, 2011.

[4] Soughnessy, R.J., Soughnessy, U.H, Nevalainen, A., Moschandreas, D., A preliminary study on Association between ventilation rates in classrooms and students performance. Indoor Air 16, pp. 465-468, 2006.

[5] Hall, R., Hardin, T., Ellis, R., School indoor air quality best practices manual. Washington State Department of Health, Olympia, Washington, 1995.

[6] Lee, S., Chang, M., Indoor air quality investigations at five classrooms. Indoor Air, 9, pp. 134-138, 1999.

[7] ASHRAE "Ventilation for acceptable indoor air quality", standard 62-2007, American Society for Heating, Refrigerating and Air Conditioning Engineers, Atlanta, GA, 2007.

[8] Clements-Croome, D.J. et al., Ventilation rates in schools. Building and Environment, 43, pp. 362-367, 2008.

[9] Wargocki et al., The effects of classroom air temperature and outdoor air supply rate on the performance of school work by children. Indoor Air proceeding. Danish Technical Research, 2005.

[10] Koiv, T.-A., Indoor climate and ventilation in Tallinn school buildings. Proc. Estonian Acad. Sci. Eng., 13, 1, pp. 17-25, 2007.

[11] REHVA GUIDBOOK no.13. Indoor Environment and Energy Efficiency in Schools. 